\title{
Compêndio de Avaliação Psicológica: Interlocução entre a Pesquisa e a Prática Profissional
}

\author{
Adriana Satico Ferraz ${ }^{1}$ D \\ Universidade São Francisco, Campinas-SP, Brasil
}

\section{Resenha do Livro Compêndio de Avaliação Psicológica}

O Compêndio de Avaliação Psicológica é uma obra organizada por psicólogos que atuam como professores/ pesquisadores em universidades públicas e privadas brasileiras e que estão ligados à presidência passada e presente do Instituto Brasileiro de Avaliação Psicológica (IBAP). O lançamento do compêndio ocorreu em 2019, durante o $9^{\circ}$ Congresso Brasileiro de Avaliação Psicológica, organizado pelo IBAP e realizado em Salvador/BA. Essa pode ser considerada a maior e mais completa obra de Avaliação Psicológica no Brasil e na América do Sul.

A obra tem por objetivo divulgar o conhecimento técnico e científico para orientar psicólogos e estudantes de Psicologia no processo de Avaliação Psicológica (AP). O compêndio possui 60 capítulos distribuídos em seis seções que tratam dos fundamentos da AP, os seus aspectos históricos e profissionais, a sua aplicação em contextos específicos, a apresentação de construtos cognitivos e híbridos, a avaliação da personalidade e, de transtornos mentais e quadros patológicos. Esses capítulos foram escritos por psicólogos, atuantes no contexto da docência, da pesquisa e da prática em AP.

A seção 1 do Compêndio de Avaliação Psicológica possuí oito capítulos, cujo tema central são os Fundamentos da Avaliação Psicológica. O primeiro capítulo, "O que é avaliação psicológica?”, procura definir a AP e as suas contribuições para o desenvolvimento teórico e metodológico da Psicologia. Na sequência, em "Propriedades psicométricas dos testes psicológicos”, é apresentada a definição e a importância das evidências de validade, das estimativas de precisão e da normatização dos instrumentos psicológicos. Os capítulos 3 e 4, abordam a "Teoria clássica dos testes (TCT)" e a "Teoria de resposta ao item (TRI)", discorrendo sobre os fundamentos da Psicometria que são aplicados nas investigações das propriedades psicométricas dos instrumentos psicológicos.

Por conseguinte, no capítulo "Adaptação de instrumentos de Avaliação Psicológica", são fornecidas orientações para a adaptação de instrumentos psicológicos, tanto no aspecto linguístico como contextual. Em "Testagem universal: avaliação psicológica e pessoas com deficiência”, é agregado ao processo de AP instrumentos desenvolvidos para serem acessíveis tanto para pessoas com deficiência como para serem utilizados por psicólogos que possuem alguma necessidade especial. O capítulo 7, "Testes informatizados", apresenta os instrumentos psicológicos cuja aplicação e correção ocorrem em formato digital como uma forma de otimizar o processo de AP. Essa seção termina com o capítulo "Integração de resultados qualitativos e quantitativos", direcionado a orientar os psicólogos sobre formas possíveis de integrar os dados quantitativos e qualitativos na fase final do processo de AP.

Com seis capítulos, a Seção 2, "Aspectos históricos e profissionais da avaliação psicológica", inicia-se contando a história da AP no mundo e no Brasil (Capítulos 9 e 10). Nos dois capítulos subsequentes são apresentados o sistema Conselhos e o Sistema de Avaliação de Testes Psicológicos (SATEPSI) e o trabalho realizado pela comissão do SATEPSI na conferência das qualidades mínimas dos instrumentos para compor a lista dos testes psicológicos aprovados para o uso do psicólogo. O capítulo 13, "Ética na avaliação psicológica: uma perspectiva internacional", engloba os aspectos éticos a serem seguidos na construção e adaptação dos testes psicológicos, bem como na utilização desses instrumentos no processo de AP. O último capítulo dessa seção, "Avaliação psicológica por meio das novas tecnologias de informação e comunicação", discorre sobre a Resolução no 11/2018 do Conselho Federal de Psicologia, que versa sobre a regulamentação da prática da AP nos atendimentos psicológicos realizados por meio das novas tecnologias de informação e comunicação.

A seção 3, aborda 15 capítulos e é intitulada "A prática da avaliação psicológica". No capítulo "Avaliação psicológica clínica" são descritas as etapas do processo de AP no contexto clínico, desde o psicodiagnóstico até a elaboração do relatório psicológico. Em "Avaliação psicológica 
hospitalar", é proposta uma estruturação do processo de AP para orientar os psicólogos que atuam no hospital. O capítulo 17, intitulado "Avaliação psicológica de fatores humanos em ambientes isolados, confinados e extremos (ICE)" traz um campo emergente da Psicologia, que aplica a AP para investigar e propor ações interventivas referentes aos riscos e aspectos estressores de pessoas que habitam e/ou trabalham nesses ambientes.

A AP direcionada ao esporte é abordada no Capítulo 18, "Avaliação psicológica no contexto do esporte", com ênfase para a promoção de melhorias no desempenho do atleta, bem como na satisfação com o esporte e na prática de exercícios físicos. A "Avaliação psicológica no adulto" (Capítulo 19) descreve o processo de AP de adultos e traz a relação de testes psicológicos aprovados pelo SATEPSI voltados a esse público. Sob o título "Elaboração de laudo/relatório psicológico: normativas e reflexões críticas", o capítulo 20 apresenta a estrutura do relatório/laudo psicológico, os diferentes contextos em que esses documentos são exigidos e disponibilizados, além de orientações para integrar os dados e fontes de informação coletadas no processo de AP. Por sua vez, o capítulo 21, "Entrevista psicológica no contexto clínico", traz possibilidades de aplicação da entrevista como um instrumento voltado ao processo de AP.

No capítulo 22, "Avaliação psicológica aplicada aos processos de escolha e transição de carreira", são indicadas as formas de avaliação no processo de Orientação Profissional e de Carreira baseadas em perspectivas teóricas que consideram os aspectos individuais das pessoas que buscam por esses atendimentos. Em "Avaliação neuropsicológica", são apresentadas as etapas desse tipo de avaliação, considerando as principais funções cognitivas e a recomendação de instrumentos para mensurá-las. O capítulo 24 trata da "Avaliação psicológica infantil", além de apresentar os aspectos gerais para a atuação do psicólogo com o público infantil, é feita a indicação da avaliação terapêutica como uma possibilidade de atendimento com crianças. O capítulo seguinte versa sobre a "Avaliação psicológica de famílias e casais", em que são expostas as principais demandas desse tipo de atendimento, com destaque para a avaliação da qualidade das relações afetivas, a interação familiar e as mudanças na estrutura familiar.

Ainda na seção 3, o capítulo 26, "Avaliação psicológica no contexto do trânsito", apresenta as inúmeras formas de aplicação da AP no trânsito, que vai desde o processo de obtenção da Carteira Nacional de Habilitação até a proposição de políticas públicas voltadas às melhorias na infraestrutura e à redução de acidentes. Em "Avaliação psicológica no contexto forense", a AP é direcionada às demandas jurídicas, em situações que requerem a participação do psicólogo na investigação de possíveis agressores e vítimas de crimes. O capítulo 28, "Violência: instrumentos para identificação, rastreio e avaliação", centraliza-se nas manifestações de violência contra crianças e adolescentes, cometida por parceiros íntimos (principalmente em relação à mulher) e a violência escolar (ex.: bullying). Por último, o capítulo "Estados de flow: definição e interfaces com o contexto do trabalho", tem por base a AP na perspectiva da Psicologia Positiva e focaliza o prazer proporcionado pelo estado de flow nas atividades laborais.

A seção 4, "Construtos cognitivos e híbridos", com nove capítulos, inicia com a "Avaliação psicológica da inteligência", descrevendo as habilidades gerais e específicas do modelo de Cattel-Horn-Carroll (CHC) de inteligência e os respectivos testes para crianças e adultos aprovados pelo SATEPSI. Em "Avaliação psicológica e criatividade", são apontados os benefícios de avaliar a criatividade, os métodos e os instrumentos que podem ser utilizados no processo de AP, com foco para os aspectos cognitivos, conativos (atitudes, interesses e personalidade), emocionais, ambientais e do desempenho criativo. O capítulo 32, "Instrumentos de avaliação das habilidades sociais no Brasil", alude aos instrumentos de avaliação dessas habilidades nas diferentes fases do desenvolvimento humano, considerando também as demandas do ciclo vital e culturais (ex.: cuidado familiar com idosos, namoro), nos diferentes papéis sociais e profissionais (ex. pais e professores como agentes educativos) e em aspectos que podem interferir nas relações interpessoais, como a ansiedade e a drogadição.

Dando prosseguimento a essa seção, o capítulo 33, "Avaliação psicológica e atenção", refere-se à AP da atenção nas modalidades tradicional e informatizada, tratando principalmente das queixas de Transtorno de Déficit de Atenção e Hiperatividade. No capítulo 34, "Avaliação psicológica da leitura e escrita", são apresentados os aspectos a serem considerados na avaliação de habilidades linguísticas ligadas ao processo de escolarização, a saber, a leitura e a escrita. Em "Metacognição: mensuração e desafios em avaliação psicoeducacional", a avaliação da metacognição enfatiza o ensino e a aprendizagem, sendo abordada por meio de instrumentos que focam as estratégias de aprendizagem e o monitoramento metacognitivo de alunos da educação básica e do ensino superior. O próximo capítulo da seção 4, "Avaliação psicológica e memória", traz um panorama dos estudos sobre a memória, indica os seus avanços na AP no Brasil e em outros países e é finalizado com um estudo de caso. O capítulo 37, intitulado "Inteligência emocional", apresenta os instrumentos de avaliação desse construto com foco para o campo da pesquisa em Psicologia. Por último, em "A habilidade de mindfulness", são descritos os conceitos e práticas centralizadas no mindfulness.

Os 12 capítulos da seção 5 destinam-se à "Avaliação da Personalidade". O primeiro capítulo explora a "Avaliação da personalidade no Brasil utilizando métodos projetivos", e aborda a avaliação do funcionamento psíquico da pessoa por meio de métodos projetivos com a finalidade de compreensão sobre a demanda (queixa) e auxiliar na 
orientação de tratamentos e encaminhamentos. O capítulo 40, "Avaliação de habilidades socioemocionais e traços de personalidade em crianças", focaliza a avaliação dessas habilidades em alunos, com base no Modelo dos Cinco Grandes Fatores de Personalidade, composto pela extroversão, neuroticismo, abertura à experiência, socialização e a conscienciosidade. Na sequência, em "Avaliação da personalidade e o modelo dos cinco grandes fatores", reporta as possibilidades de mensuração da personalidade com base no modelo que dá nome ao capítulo. A "Teoria dos cinco grandes fatores de personalidade (TFC): uma introdução teórico-conceitual e aplicação para avaliação", é um capítulo que também se fundamenta no Modelo dos Cinco Grandes Fatores de Personalidade e apresenta um estudo de caso para ilustra-lo no processo de AP.

Em "Avaliação da personalidade em crianças", são feitas indicações sobre os objetivos do processo de avaliação da personalidade no público infantil, no sentido de verificar se a queixa provém de padrões naturais da fase do desenvolvimento infantil ou de comportamentos inadequados, mas que são transitórios e que muitas vezes acabam sendo reforçados pelo ambiente. No capítulo 44, "Avaliação da inteligência emocional e da personalidade: aproximações e distinções", a inteligência emocional é concebida como uma habilidade cognitiva e como um traço de personalidade, sendo que o processo de AP desses construtos ainda se restringe ao âmbito das pesquisas.

Em continuidade à seção 5 , o capítulo 45 , "O teste de Rorschach e a personalidade em ação" esclarecem que a utilização desse teste no processo de AP tem por finalidade mobilizar os aspectos cognitivos e afetivos que, quando combinados, evidenciam as características de personalidade da pessoa. No capítulo "Avaliação dos traços sombrios da personalidade", são apresentados os conceitos e os instrumentos de avaliação dos traços sombrios da personalidade. Esses traços fazem parte da Tríade Sombria, composta pelo maquiavelismo, narcisismo e a psicopatia. Em seguida, na "Introdução às forças de caráter", o capítulo aborda o conteúdo baseado na Psicologia Positiva. Nele, é feita a indicação de que a avaliação das características positivas das pessoas (ex.: bondade e a gratidão) auxiliam na compreensão do seu funcionamento e fornece meios para desenvolvê-las, sendo uma forma de promoção de bem-estar psicológico.

Ainda na seção 5, o capítulo 48 traz a "Avaliação de transtornos da personalidade no Brasil: panorama geral e ferramentas disponíveis". Nesse capítulo, os diagnósticos dos transtornos da personalidade são apresentados tanto na perspectiva do Manual Diagnóstico e Estatístico dos Transtornos Mentais (DSM-5) como no modelo em psiquiatria Hierarchical Taxonomy of Psychopathology (HiTOP). Outro campo emergente da Psicologia é apresentado no capítulo 49, "Digital phenotyping: perspectivas futuras para a avaliação e diagnóstico dos transtornos de personalidade". O Digital Phenotyping refere-se à interação da pessoa com o ambiente virtual (ex.: redes sociais) e relaciona esse uso com o diagnóstico, o tratamento e o gerenciamento de doenças crônicas. No capítulo 50, "Avaliação e diagnóstico dos transtornos da personalidade: modelo categórico, dimensional e híbrido", são expostas as especificidades dessas três formas diagnósticas aplicadas à diferenciação da personalidade saudável da patológica.

Por fim, a seção 6 reúne 10 capítulos sobre a "Avaliação de transtornos mentais e quadros patológicos". O capítulo 51, "Avaliação psicológica na esquizofrenia" aborda a AP no diagnóstico e na elaboração de planos de tratamento da esquizofrenia em todas as fases do desenvolvimento humano. Em "Avaliação psicológica no suicídio", recomenda-se que no processo de AP sejam utilizadas estratégias multimétodos, por meio de entrevistas e testes psicológicos padronizados. $\mathrm{Na}$ sequência, em "Avaliação psicológica no estresse", é feita a indicação sobre a crescente produção científica sobre o tema. No capítulo 54, "Avaliação psicológica para os transtornos de ansiedade", são destacadas as estratégias de avaliação voltadas ao diagnóstico e ao tratamento da ansiedade na área da Psicologia Clínica, sob o fundamento da Terapia Cognitivo-Comportamental.

No capítulo seguinte, intitulado "Avaliação psicológica dos transtornos alimentares", apresentam-se métodos para avaliar os sintomas da anorexia nervosa, da bulimia nervosa e do transtorno de compulsão alimentar, com destaque para a investigação da imagem corporal. No capítulo 56, a "Avaliação em psicopatologia", é abordada por meio das técnicas de avaliação aplicadas no formato dos testes de autorrelato, projetivos, do tipo construtivo, observacionais e do heterorrelato. Por conseguinte, em "Avaliação da sintomatologia depressiva", a depressão é caracterizada como uma doença de causas multifatoriais. À vista disso, no processo de AP, o psicólogo deve utilizar diversos instrumentos de avaliação e cruzar os dados obtidos com outras fontes de informação, sobretudo, com o histórico de vida da pessoa.

Em "Avaliação do trauma psicológico", são apresentadas as formas de avaliar o estresse pós-traumático e o estresse traumático secundário, baseado nos avanços das pesquisas em AP que vem proporcionando a ampliação do conhecimento à respeito da avaliação e da indicação de tratamentos compatíveis com a exposição direta ou indireta ao trauma. No capítulo 59, referente à "Avaliação psicológica dos transtornos relacionados a substâncias psicoativas", os instrumentos psicológicos abordados são destinados à avaliação do padrão de consumo e dos prejuízos em decorrência do uso de substâncias psicoativas, bem como para investigar o nível de dependência, fissura, motivação e a expectativa das pessoas sobre os efeitos das drogas. Essa seção se encerra com o capítulo "Avaliação psicológica e transtornos do neurodesenvolvimento", com foco para o processo de AP voltada à investigação de deficiência intelectual e dos transtornos de comunicação, do espectro autista, do déficit de atenção/hiperatividade, específico da aprendizagem e motores. 
Mediante o exposto, o Compêndio de Avaliação Psicológica pretende contribuir para a formação de futuros psicólogos, bem como para auxiliar na atuação de profissionais já formados no processo de AP, tanto no campo da pesquisa como na prática aplicada às diferentes áreas da Psicologia. Cada seção dessa obra afirma a necessidade do preparo do psicólogo, com ênfase para o domínio teórico das especificidades do público atendido/ investigado e a apropriação do conhecimento dos construtos e habilidades a serem avaliadas por meio de instrumentos adequados.

Visto que a AP se encontra em expansão, sugere-se que essa obra seja ampliada em uma segunda edição. Nesse sentido, recomenda-se o acréscimo dos avanços em pesquisas nas áreas clássicas e emergentes da Psicologia, desenvolvidas por profissionais ligados ao IBAP, instituição essa que vem trabalhando no desenvolvimento e na representação da $\mathrm{AP}$ em diversos órgãos e instituições da Psicologia no Brasil.

\section{Agradecimentos}

Não há menções.

\section{Financiamento}

A presente resenha não recebeu nenhuma fonte de financiamento sendo custeada com recursos da própria autora.

\section{Contribuições dos autores}

Declaro que Adriana Satico Ferraz participou da elaboração integral desta resenha, a saber, a redação inicial e final, bem como a revisão e edição do manuscrito.

\section{Disponibilidade dos dados e materiais}

Esse tópico não se aplica para resenhas.

\section{Conflito de interesses}

A autora declara que não há conflitos de interesses.

\section{Referência}

Baptista, M. N., Muniz, M., Reppold, C. T., Nunes, C. H. S. S., Carvalho, L. F., Primi, R., ... Pasquali, L. (2019). Compêndio de Avaliação Psicológica. Petrópolis, RJ/Vozes.

\section{Sobre a autora}

Adriana Satico Ferraz é psicóloga e Mestre em Psicologia (linha de pesquisa Avaliação Psicológica Educacional) pela Universidade São Francisco, Campus Swift, Campinas/SP. Atualmente é doutoranda em Psicologia pela mesma instituição.

\section{Como citar este artigo}

Ferraz, A. S. (2021). Compêndio de Avaliação Psicológica: Interlocução entre a Pesquisa e a Prática Profissional. Avaliação Psicológica, 20(1), 122-125. http://dx.doi.org/10.15689/ap. 2021.2001.20084.13 